\title{
Formulation and evaluation of matrix microspheres for simultaneous delivery of salbutamol sulphate and theophylline
}

\author{
L Pachuau*, S Sarkar and B Mazumder \\ Department of Pharmaceutical Sciences, Dibrugarh University, Dibrugarh-786004
}

\begin{abstract}
Purpose: The objective of this study was to formulate and evaluate a matrix microsphere system for simultaneous delivery of two anti-asthmatic drugs Salbutamol sulphate and Theophylline which are often indicated for the management of asthma, their frequent dosing may reduce compliance, thus making a prolonged release formulation necessary. Ethylcellulose was used as a retardant polymer and its compatibility with the drugs and the drug-drug compatibility were established through IR, XRD and DSC studies.

Method: Microspheres were prepared by emulsion solvent evaporation using acetone/light liquid paraffin system. Tween 80 was used as the dispersing agent and cyclohexane was added to harden the microspheres. The prepared microspheres were characterized for their micromeritic properties and drug loading, as well as by infrared spectroscopy (IR), differential scanning calorimetry (DSC), x-ray powder diffractometry (XRD) and scanning electron microscopy (SEM). The in vitro release studies were performed in $\mathrm{pH}$ 7.4, phosphate buffer.

Result: The prepared microspheres were white, free flowing and spherical in shape. The drug-loaded microspheres showed 67-91\% of entrapment and release was extended upto 6 to $8 \mathrm{~h}$. The infrared spectra, differential scanning calorimetry thermographs and XRD spectra all showed the stable character of both the drugs in the drug-loaded microspheres and revealed the absence of drug-polymer interactions. Scanning electron microscopy study revealed that the microspheres were spherical and porous in nature.

Conclusion: The matrix microspheres have a potential for the prolongation and simultaneous delivery of the anti asthmatic drugs (salbutamol and theophylline).
\end{abstract}

Keywords: Matrix microspheres, Salbutamol sulphate, Theophylline, Ethylcellulose, Emulsion solvent evaporation technique.

${ }^{\star}$ Corresponding author: E-mail: aduha_pc@yahoo.co.in 


\section{INTRODUCTION}

Patients suffering from chronic diseases like asthma, diabetes and epilepsy may have to take drugs everyday for the rest of their life ${ }^{3}$. WHO estimates the number of asthmatic patients to be around 100 to 150 millions around the world and India contribute $10 \%$ of the total and its incidence is escalating every decade at an alarming rate. In management of chronic diseases like asthma, compliance to the dosage regimen is the key to a successful therapy. Patient may be treated with more than one drug and compliance is found to be low in such cases.

The short half life (4 to 6 hours) with extensive first pass metabolism of salbutamol and the propensity for interaction and narrow therapeutic index (10 to $20 \mu \mathrm{g} / \mathrm{ml}$ ) of theophylline are well known. Although salbutamol and theophylline are often indicated for the management of asthma, their frequent dosing may reduce compliance, thus making a prolonged release formulation necessary. Theophylline produced an additive effect when used in combination with salbutamol sulphate ${ }^{4}$. Different controlled release dosage forms for simultaneous delivery of salbutamol and theophylline have been proposed by different authors. These include transdermal patches ${ }^{5}$, Matrix tablets ${ }^{6}$ and Osmotic pump tablets ${ }^{7}$. Both salbutamol and theophylline are readily and well absorbed along the gastrointestinal tract. Even when salbutamol is given as an inhalation, it has been suggested that majority of the dose is swallowed and absorbed from the gut ${ }^{8}$. Microencapsulation is used to modify and retard drug release. Microspheres, due to its small particle size, are widely distributed throughout the gastrointestinal tract which improves drug absorption and reduces sideeffects due to localized build-up of irritating drugs against the gastrointestinal mucosa ${ }^{9}$.

The objective of the present study includes: (a) formulation of a sustained release matrix microsphere system containing salbutamol sulphate and theophylline using ethylcellulose as the retardant polymer which will release the drug at the gastrointestinal tract for a prolong duration to promote patient compliance; (b) to study the effects of drug to polymer ratio on in-vitro drug release and (c) to fit the drug release data to various drug release models.

\section{MATERIALS AND METHODS Materials}

The test drugs, salbutamol sulphate IP and anhydrous theophylline IP (Ducbill drugs, Kolkatta), the polymeric matrix former ethylcellulose (22 cps grade determined at 80:20 toluene: ethanol, Wilson Brothers, Mumbai), and the dispersing agent Tween 80 (Rankem, New Delhi) were obtained and all other chemicals and reagents used were of analytical grade.

\section{Determination of Saturation solubility}

The saturation solubility of both Anhydrous theophylline and salbutamol sulphate were separately determined at distilled water and phosphate buffer $\mathrm{pH} 7.4$ to observe the suitability of the solution as a dissolution medium (Table 2). Excess amount of the drugs were taken and dissolved in a $1 \mathrm{ml}$ of phosphate buffer ( $\mathrm{pH}$ 7.4) and distilled water and extracted for 24 hours. After suitable dilutions, the concentrations were determined spectrophotometrically at $276 \mathrm{~nm}$ for salbutamol sulphate and $270.5 \mathrm{~nm}$ for Theophylline ${ }^{10}$.

\section{Preparation of microspheres}

The microspheres were prepared by emulsion solvent evaporation technique using the formulation as shown in Table 1. In this method $1219.2 \mathrm{mg}$ of ethylcellulose was dissolved in $15 \mathrm{ml}$ of acetone and a given amount of the drugs were dispersed in it to make different drug to polymer ratio of $1: 1,1: 2$ and $1: 3$ and stirred for about 10 minutes. Then the polymer drug dispersion was poured into $50 \mathrm{ml}$ of liquid paraffin (light) containing varying concentrations of Tween 80 . The whole system was then stirred for about 4 hours at 900 RPM. After stirring process is over the liquid paraffin (light) was decanted off and the microspheres formed were collected 
by filtration in a Whatman filter paper and washed with Cyclohexane to completely

Drug entragment efficiency $=\frac{\text { Experinental drug content }}{\text { Initial drug content in the formulation }} \times 100 \quad \ldots .1$

remove the remaining oil and dried at $50{ }^{\circ} \mathrm{C}$ in Vacuum drier (NSW, India) for 6 hours and collected for further studies.

\section{Particle size determination}

The particle size of the microspheres was determined by microscopic method ${ }^{11}$. For each batch of the microspheres, 100 particles were counted and done in triplicate.

\section{Drug entrapment efficiency}

The amounts of salbutamol sulphate and theophylline present in the microsphere were determined by extraction in distilled water ${ }^{12}$. $50 \mathrm{mg}$ of the crushed and powdered microsphere was taken and extracted in $50 \mathrm{ml}$ of distilled water and stirred for 15 minutes at $1500 \mathrm{rpm}$. The solution was filtered and diluted with $0.05 \mathrm{M} \mathrm{NaOH}$ and absorbance

Drug entrapment efficiency $=\frac{\text { Egperimental dougcontent }}{\text { Iafinal drug content in the furmulation }} \times 100 \ldots 2$

measured spectrophotometrically (U-2001, Hitachi) at $244.6 \mathrm{~nm}$ and $276.5 \mathrm{~nm}$ and concentrations were determined by employing simultaneous equations method ${ }^{10,5}$.

\section{In vitro drug release study}

The in-vitro release study of the microsphere was carried out using USP rotating basket method at $50 \mathrm{rpm}$ at $37^{\circ} \mathrm{C}$. Dissolution study was performed in Phosphate buffer $\mathrm{pH} 7.4$ taking $900 \mathrm{ml}$ for each study. $100 \mathrm{mg}$ of the microsphere was placed in the dissolution medium and test samples were taken from the medium at predetermined time intervals over a period of 12 hours and the samples were analyzed for salbutamol sulphate and theophylline content UV spectrophotometer.

\section{Infrared Spectroscopy}

IR spectra of the pure drugs and microspheres were recorded using Perkin-
Elmer model 883 IR-spectrophotometer between the ranges of 500 to $4000 \mathrm{~cm}^{-1}$ by making a pellet of the samples with $\mathrm{KBr}$. The resultant spectra were then compared with standard reference (IP 1996) and observe for any type of deviation from the standard.

Differential Scanning Calorimeter Analysis (DSC)

DSC thermogram of the pure drugs and the microspheres were recorded with a differential scanning calorimeter (Universal V2.5H TA Instrument) from 20 to $550{ }^{\circ} \mathrm{C}$ at a heating rate of $20 \stackrel{\circ}{ } \mathrm{C} /$ minute.

\section{$X$-Ray Diffraction Spectroscopy (XRD)}

$X$-ray diffraction spectrum of the pure drug and microspheres were recorded with Phillips PW 1830 X-ray generator fixed with PW 1710 diffractometer (Phillips Industrial \& Electroacoustic Systems Division, Almelo, The Netherlands). The XRD was performed at the angle between $5-60^{\circ} 2 \theta$.

\section{Scanning Electron Microscopy (SEM)}

Scanning electron microscopy (Hitachi S$3600 N$, Japan) was done to characterize surface topography of the microspheres. Photomicrograph of the microspheres before and after the release of drugs was taken. The quality of the microspheres (with respect to surface properties) and the nature and size of pores developed on the surface can be studied. The changes that occur during in-vitro dissolution studies may have implications to the performance of the microspheres.

\section{Release Kinetics}

Data obtained from in vitro release studies were fitted to various kinetic equations to find out the mechanism of drug release from the ethylcellulose microsphere. The kinetic models used were:

$Q_{t}=k_{o} t \quad$ (zero-order equation) $\quad \ldots 3$

$\ln Q_{t=} \ln Q_{0} . k_{1} t$ (first-order equation) ...4 
Table 1: Formulation, drug entrapments and mean particle size of microspheres

\begin{tabular}{lcccccc}
\hline $\begin{array}{c}\text { Formulation } \\
\text { code }\end{array}$ & $\begin{array}{c}\text { Salbutamol } \\
\text { sulphate } \\
(\%)\end{array}$ & $\begin{array}{c}\text { Theophylline } \\
(\%)\end{array}$ & $\begin{array}{c}\text { Mean } \\
\text { particle size } \\
(\boldsymbol{\mu m})\end{array}$ & $\begin{array}{c}\text { Amount of } \\
\text { polymer } \\
(\mathbf{m g})\end{array}$ & $\begin{array}{c}\text { Amount of } \\
\text { theophylline } \\
(\mathbf{m g})\end{array}$ & $\begin{array}{c}\text { Amount of } \\
\text { salbutamol } \\
\text { sulphate } \\
(\mathbf{m g})\end{array}$ \\
\hline T1 & $78.667 \pm 2.45$ & $82.862 \pm 1.75$ & $730.55 \pm 1.582$ & 1219.2 & 1200 & 19.2 \\
T2 & $76.534 \pm 3.67$ & $83.468 \pm 1.32$ & $689.71 \pm 1.281$ & 1219.2 & 600 & 9.6 \\
T3 & $83.45 \pm 1.25$ & $86.789 \pm 0.986$ & $695.64 \pm 2.565$ & 1219.2 & 400 & 6.4 \\
\hline
\end{tabular}

Table 2: Correlation coefficient $\left(r^{2}\right)$, Constant $(K)$ and Diffusion exponent $(n)$ after fitting of dissolution data into various release kinetic models Theophylline

\begin{tabular}{ccccccccc}
\hline $\begin{array}{c}\text { Formulation } \\
\text { (Drug:Polymer) }\end{array}$ & Zero-Order & \multicolumn{2}{c}{ First-Order } & \multicolumn{2}{c}{$\begin{array}{c}\text { Higuchi } \\
\text { Model }\end{array}$} & \multicolumn{2}{c}{$\begin{array}{c}\text { Korsenmeyer- } \\
\text { Peppas Model }\end{array}$} \\
& $\mathbf{r}^{2}$ & $\mathrm{~K}_{\mathrm{o}}$ & $\mathbf{r}^{2}$ & $\mathrm{~K}_{1}$ & $\mathbf{r}^{2}$ & $\mathrm{~K}_{\mathrm{h}}$ & $\mathbf{r}^{2}$ & $\mathrm{n}$ \\
\hline
\end{tabular}

Theophylline

$\begin{array}{lllllllll}1: 1 & 0.7406 & 6.9769 & 0.9707 & 0.104 & 0.9842 & 26.287 & 0.9907 & 0.2506 \\ 1: 2 & 0.7908 & 5.5131 & 0.9687 & 0.068 & 0.9523 & 23.334 & 0.9926 & 0.2798 \\ 1: 3 & 0.8461 & 4.4599 & 0.955 & 0.037 & 0.9782 & 18.44 & 0.9902 & 0.2334\end{array}$

Salbutamol

Sulphate

$\begin{array}{lllllllll}1: 1 & 0.767 & 9.5228 & 0.9579 & 0.213 & 0.9525 & 33.335 & 0.9811 & 0.4225 \\ 1: 2 & 0.7951 & 6.8991 & 0.9873 & 0.131 & 0.9879 & 27.889 & 0.9919 & 0.4447 \\ 1: 3 & 0.8671 & 4.8203 & 0.9636 & 0.043 & 0.9763 & 19.903 & 0.9973 & 0.3037\end{array}$

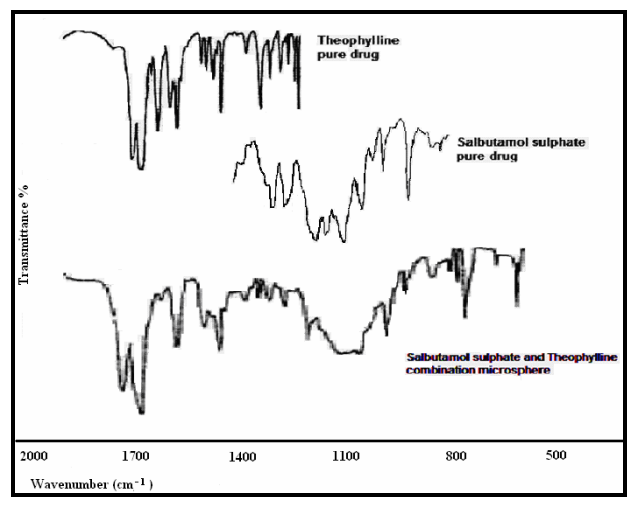

Figure 1: IR spectra salbutamol sulphate (pure drug), theophylline (pure drug) and microsphere containing the two druas (1:3 drua:Dolvmer). 
$Q_{t=}$ K.S. $V_{t}=k_{H} \cdot V_{t} \quad \ldots \ldots \ldots \ldots . .5$

(Higuchi eqn based on Fickian diffusion)

Where, $Q$ is the amount of drug release in time t, $Q_{0}$ is the initial amount of drug in the microsphere, $S$ is the surface area of the microcapsule and $k_{o}, k_{1}$, and $k_{H}$ are rate constant of zero order, first order and Higuchi rate equations respectively. In addition to these basic release models, there are several other models as well. One of them is Peppas and Korsenmeyer equation ${ }^{13,14}$ (power law).

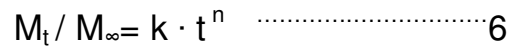

Where $M_{t}$ is the amount of drug release at time $t$ and $M_{\infty}$ is the amount release at time $t=$ $\infty$, thus $M_{t} / M_{\infty}$ is the fraction of drug released at time $\mathrm{t}, \mathrm{k}$ is the kinetic constant, and $n$ is the diffusion exponent which can be used to characterize both mechanism for both solvent penetration and drug release. Determining the correlation coefficient assessed fitness of the data into various kinetic models. The rate constants, for respective models were also calculated from slope.

\section{RESULTS}

The physicochemical compatibility of the drugs and the polymer was established through infrared spectroscopy (Figure 1), differential scanning colorimetry and x-ray diffraction spectroscopy. Results from IR, DSC and XRD studies do not show any interaction or degradation.

Scanning Electron Microscopy (SEM): Scanning electron microscopy of drugs-loaded ethylcellulose microspheres (Figure 2) reveals that the microspheres posses a rough and rugged surface. The micrograph taken after 12 hours release studies also reveals porosity developed at the surface. The micrographs show that porosity developed but structure is retained as 12 hours drug release study was carried out.

Entrapment Efficiency: The entrapment efficiency determined at phosphate buffer of $\mathrm{pH} 7.4$ shows the entrapment efficiency of both drugs increase as the polymer concentration is increased (Table 1). The entrapment efficiency for salbutamol sulphate was in the range of 78 (for 1:1 drug:polymer) to 83 (for 1:3 drug:polymer) and for theophylline it was in the range of 82 (for $1: 1$ Drug:Polymer) to 86 (for 1:3 Drug:Polymer).

Mean Particle Size: The particle size of the microspheres (Table 1 ) was in the range of $690 \mu \mathrm{m}$ to $730 \mu \mathrm{m}$.

Drug Release: The effect of variation in drug to polymer ratio on drug release was studied on salbutamol sulphate and theophylline combination microspheres in a dissolution medium of phosphate buffer of $\mathrm{pH} 7.4$. Different drug to polymer ratio taken were 1:1, $1: 2$ and 1:3 and increase in polymer concentration resulted in a decrease of drugs release rate. The release of salbutamol sulphate was found to be higher as compared to theophylline release. Sustained release up to 12 hours was achieved when drug: polymer was taken up to 1:3.

The release data obtained were fitted into various release kinetic models and release kinetics table (Table 2) was prepared.

\section{DISCUSSION}

A matrix microsphere system for sustain release of two drugs has been formulated. For this type of system it is important that the presence of one drug species do not alter the physicochemical properties of the other ${ }^{13}$.

Scanning electron microscopy of drugs-loaded ethylcellulose microspheres reveals that the microspheres posses a rough and rugged surface. It was also observed that after dissolution was performed, bigger and more pores are developed. The surface porosity is crucial for drug release in microspheres prepared with ethylcellulose. Since the polymer is not biodegradable, the release of the drugs from microspheres takes place by dissolution and diffusion through the pores. Ethylcellulose allows water to permeate through its surface without itself dissolving in it. The micrographs show that porosity developed but structure is retained as 12 hours drug release study was carried out.

The entrapment efficiency of both drugs was found to increase as the polymer concentration is increased, as there were more polymeric binding sites for the drugs. And as the amount of drug taken is decreased 
Pachuau et al
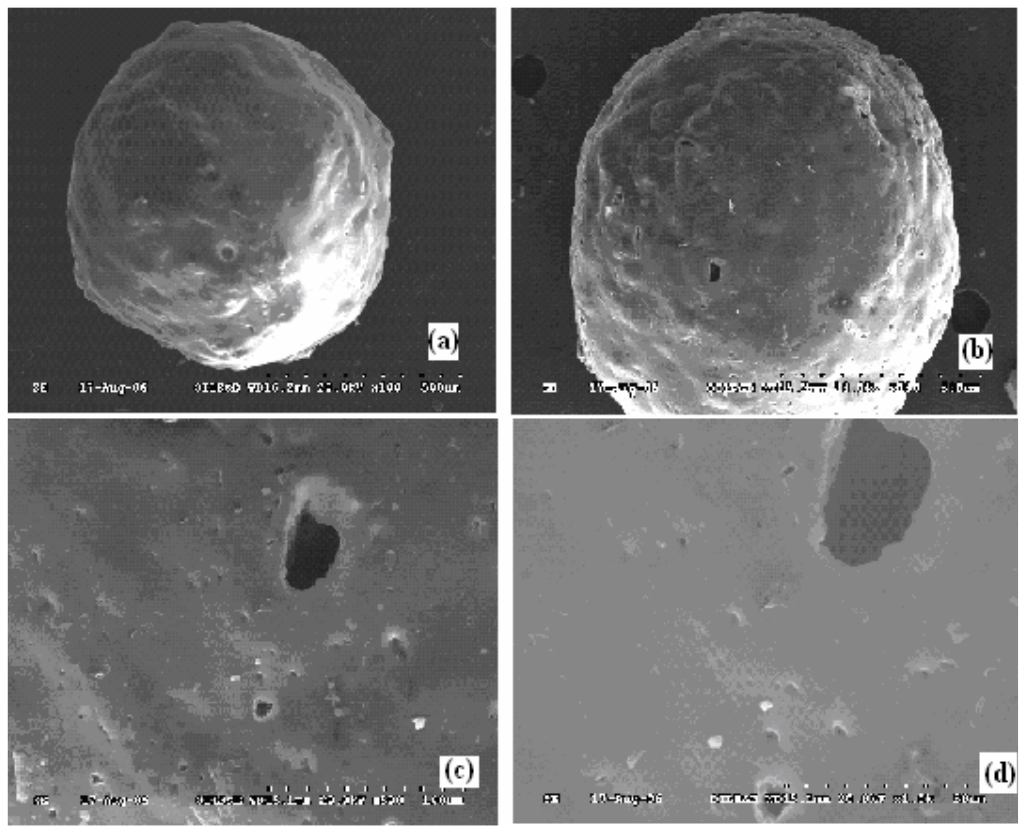

Figure 2: Scanning electron micrographs of salbutamol sulphate-theophylline combination microsphere (1:3 drug:polymer) (a) before drug release; (b) after 12 hours of drug release; (c) and $(d)$ show magnifications of (b).

Figure 3: Higuchi plots for drug release from microsphere (1:2, drug:polymer, 1\% Tween 80)

while taking constant amount of the polymer, the particle size is decreasing. This may be due to the decrease in viscosity of the drugpolymer dispersion since constant amount of polymer was dissolved in acetone and the amount of drug taken was reduced to obtain a higher polymer concentration ${ }^{15}$.
The effect of variation in drug to polymer ratio on drug release was due to the increase in wall thickness that results in longer diffusion path $^{16}$. The release of salbutamol sulphate was found to be higher as compared to theophylline release, this may be due to the higher solubility of salbutamol sulphate than theophylline in the dissolution medium. 
Dissolution studies show a sustained release upto 12 hours when drug:polymer was taken up to $1: 3$ this may be due to an increase in the tortuosity of the diffusion pathlength as the amount of the polymer is increased. From the release data obtained and the release kinetics table (Table 2) it can be observed that the best-fit release kinetics was achieved with Higuchi plot followed by zero order and First order. The release of both the drugs was influenced by the drug to polymer ratio and was found to be diffusion controlled. So, the release of salbutamol sulphate and theophylline from the ethylcellulose microspheres was found to exhibit diffusional characteristics and closely follows Higuchi Model and also highly correlated with firstorder release model (Figure 3).

\section{CONCLUSION}

Salbutamol sulphate-theophylline combination microspheres was prepared successfully using the emulsion solvent evaporation method. Taking of different polymer:drug ratio is found to influence the size, entrapment efficiency and release characteristics of the microspheres. The assessment of the release kinetics revealed that drug release from the microspheres followed Higuchi Model. The mechanism of drug release from microspheres was diffusion-controlled. Since the polymer and the drugs were found to be compatible and the release mechanism is characterized, there is a great scope for the formulation of these antiasthmatic drugs as a microsphere system. Since microspheres are better distributed and facilitate the absorption of drugs from the intestines, this type of formulation would help in controlling asthmatic attacks to millions of patience suffering from it.

\section{ACKNOWLEDGEMENT}

Authors wish to thank Ducbill drugs, Kolkatta for their gift samples of the drugs, Dr. Rajib Goswamee, Regional Research Laboratory, Jorhat for DSC studies, Dr. R. K. Bordoloi and Dr. George, R \& D Centre, Oil India Limited, Duliajan for XRD and SEM studies, J. R. Chetia, Department of Chemistry, Dibrugarh University for IR studies. The necessary facilities provided by Department of Pharmaceutical Sciences, Dibrugarh University for conducting the research is highly appreciated.

\section{REFERENCES}

1. Mingna Song, Ning Li, Shuying Sun, Lourens $R$. Tiedt, Wilna Liebenberg, Melgardt $M$ de Villiers. Effect of viscosity and concentration of wall former, emulsifier and pore-inducer on the properties of Amoxicillin Microcapsules prepared by Emulsion Solvent Evaporation. IL Farmaco 2005; 60: 261-267

2. Amperiadou $A$, Georgarakis $M$. Controlled release salbutamol sulphate microcapsules prepared by emulsion solvent-evaporation technique and study on the release affected parameters. International Journal of Pharmaceutics 1995; 115:1-8

3. Rowland M, Tozer TN. Clinical Pharmacokinetics: Concepts and Applications, ed 3(First Indian Edition) 1996, Lea \& Febiger, Philadelphia, pp 1.

4. Nishimura $K$, Koyama $H$, lkeda $A$, Sugiura $N$, Kawakatsu K, Izumi $T$. The additive effect of theophylline on a high- dose combination of inhaled Salbutamol and Ipratropium bromide in stable COPD - chronic obstructive pulmonary disease. Chest 1995; 107: 718-723.

5. Murthy SN, Hiremath SR. Formulation and Evaluation of Controlled-Release Transdermal Patches of Theophylline-Salbutamol Sulfate. Drug Dev Ind Pharm 2001; 27: 1057-1062.

6. Dandagi PM, Mastiholimath VS, Patil MB, Manvi FV, Gadad AP, Ruchi Sharma. Development and Evaluation of Theophylline and Salbutamol sulphate Sustained Release Matrix Tablets. Indian Journal of Pharmaceutical Sciences 2005; 67(5): 598-602.

7. Prabakaran D, Paramjit Singh, Parijat Kanaujia, Jaganathan KS, Amit Rawat, Suresh $P$ Vyas. Modified push-pull osmotic system for simultaneous delivery of theophylline and Salbutamol: development and in vitro characterization. International Journal of Pharmaceutics 2004; 284: 95-108.

8. Sweetman SC. ed. Martindale: The Complete Drug Reference. ed 33, Pharmaceutical Press, London, 2002, pp 757 - 786.

9. Li SP, Kowarski CR, Feld KM, Grim WM. Recent Advances in Microencapsulation Technology and Equipment. Drug Dev Ind Pharm 1988; 14: 353-376.

10. Singhvi I, Chaturvedi SC. Three Spectrophotometric methods for simultaneous estimation of Salbutamol and theophylline from tablets. Indian Drugs 1998; 35: 421-42 6.

11. Soppimath KS, Aminabhavi TM. Ethylacetate as a dispersing solvent in the production of poly $(D L-$ lactide co-glycolide) microspheres: effect of 
Pachuau et al

process parameters and polymer type. Journal of Microencapsulation 2002; 19: 281-292.

12. Nokhodchi A, Farid D. Microencapsulation of Paracetamol by various Emulsion Techniques using Cellulose Acetate Phthalate. Pharm Tech 2002; June: 54-60.

13. Siepmann J, Peppas NA. Modeling of drug release from delivery systems based on hydroxypropyl methylcellulose (HPMC). Adv Drug Del Rev 2001; 48: 139-157.
14. Costa P, Lobo JMS. Modelling and comparison of dissolution profiles. Eur J Pharm Sci 2001; 13: 123-133.

15. Parvinder Singh, Desai SJ, Simonelli AP, William I Higuchi. Release Rates of Solid Drug Mixtures Dispersed in Inert Matrices I: Non-interacting Drug Mixtures. J Pharm Sci 1967; 56: 15421547.

16. Kim CK, Kim MJ, Oh KH. Preparation and evaluation of sustained release microspheres of terbutaline sulphate. International Journal of Pharmaceutics 1994; 106: 213-219. 